\title{
GEOTHERMAL RESEARCH AND DEVELOPMENT PROGRAM
}

\section{QUARTERLY TECHNICAL REPORT}

September - December 1992

RECEIVED

MAR 041993

OSTI

\section{DISCLAIMER}

This report was prepared as an account of work sponsored by an agency of the United States Government. Neither the United States Government nor any agency thereof, nor any of their employees, makes any warranty, express or implied, or assumes any legal liability or responsibility for the accuracy, completeness, or usefulness of any information, apparatus, product, or process disclosed, or represents that its use would not infringe privately owned rights. Reference herein to any specific commercial product, process, or service by trade name, trademark, manufacturer, or otherwise does not necessarily constitute or imply its endorsement, recommendation, or favoring by the United States Government or any agency thereof. The views and opinions of authors expressed herein do not necessarily state or reflect those of the United States Government or any agency thereof.

Work Performed Under Grant No. DE-FG07-90ID12934

For

U. S. Department of Energy

office of Industrial Technologies

Washington, D.C.

By

Standford Geothermal Program

Stanford University

Stanford, California $94305-2220$ 


\section{DISCLAIMER}

This report was prepared as an account of work sponsored by an agency of the United States Government. Neither the United States Government nor any agency Thereof, nor any of their employees, makes any warranty, express or implied, or assumes any legal liability or responsibility for the accuracy, completeness, or usefulness of any information, apparatus, product, or process disclosed, or represents that its use would not infringe privately owned rights. Reference herein to any specific commercial product, process, or service by trade name, trademark, manufacturer, or otherwise does not necessarily constitute or imply its endorsement, recommendation, or favoring by the United States Government or any agency thereof. The views and opinions of authors expressed herein do not necessarily state or reflect those of the United States Government or any agency thereof. 


\section{DISCLAIMER}

Portions of this document may be illegible in electronic image products. Images are produced from the best available original document. 


\title{
Quarterly Report for September-December 1992
}

\author{
Stanford Geothermal Program \\ Stanford University
}

January 25, 1993

\section{ADSORPTION OF WATER VAPOR ON RESERVOIR ROCKS}

This experimental project is under the direction of Research Associate Dr. Shubo Shang, and Prof. Henry J. Ramey, Jr. The focus of the work is the experimental investigation of adsorption of water onto geothermal reservoir rocks.

The results of the water adsorption/desorption tests performed on Geysers shallow reservoir core, Berea sandstone and Montiverdi \#2 samples were reported previously in the Stanford Geothermal Program Second Annual Technical Report and July-Sept. Quarterly Report (1992). In our continued effort to collect water adsorption/desorption data on a wide range of reservoir samples, we have performed a test on one of the samples from ENEL, Italy. This sample is from well Montiverdi \#2. The sample we used is from well cuttings.

Figures 1 and 2 show the adsorption/desorption isotherms obtained at - $100^{\circ}$ and $120^{\circ} \mathrm{C}$ on this sample. As shown in the figures, significant hysteresis exists in water vapor adsorption/desorption in the Montiverdi \#2 sample, similar to those reported previonsly. The origin of the hysteresis is not yet clear to us.

Figure 3 compares the adsorption isotherms obtained at temperatures of $80^{\circ}, 100^{\circ}, 120^{\circ}$ and $140^{\circ} \mathrm{C}$. Clearly, temperature has an effect on the amount of water adsorbed on this particular rock sample. Examination of the adsorption isotherms suggests that for the range of relative pressures studied, the adsorption isotherms can be well approximated by linear relationships. However, due to the problem of nonuniform heating, we were not able to 


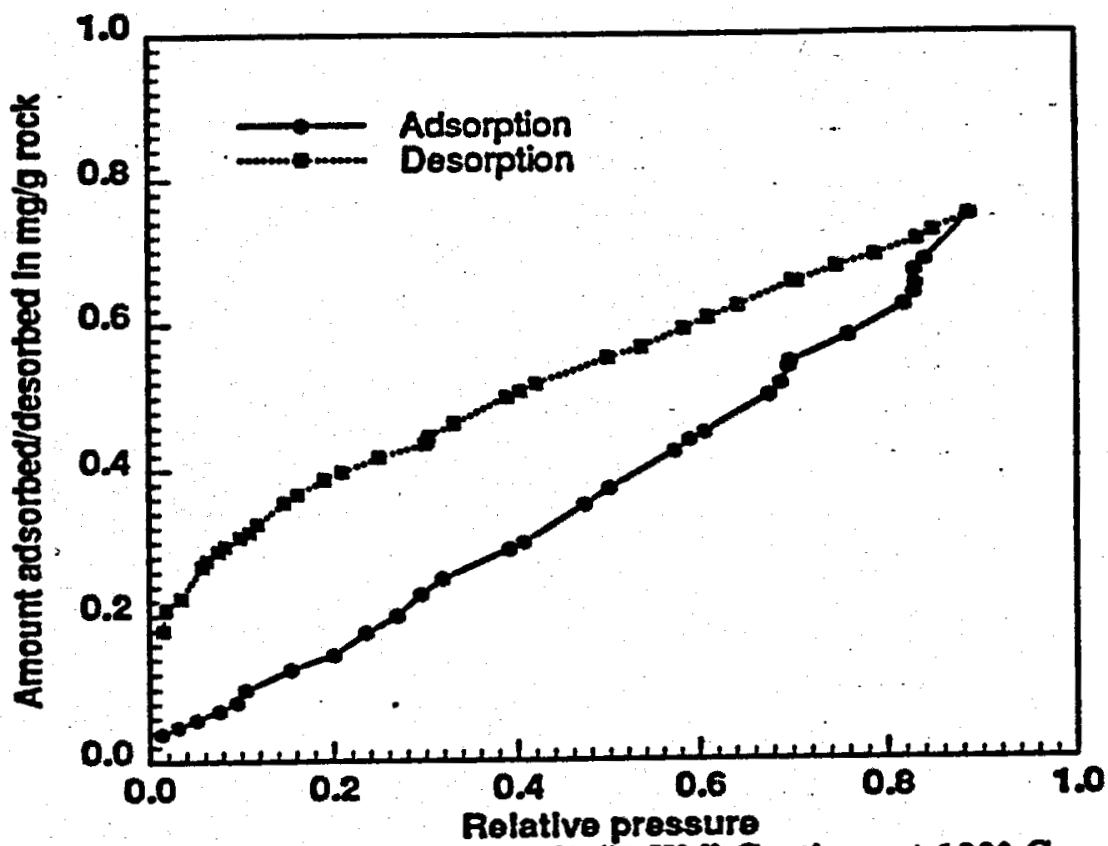

Figure 1: Isotherms on Montiverdi \#2 Well Cuttings at $100^{\circ} \mathrm{C}$

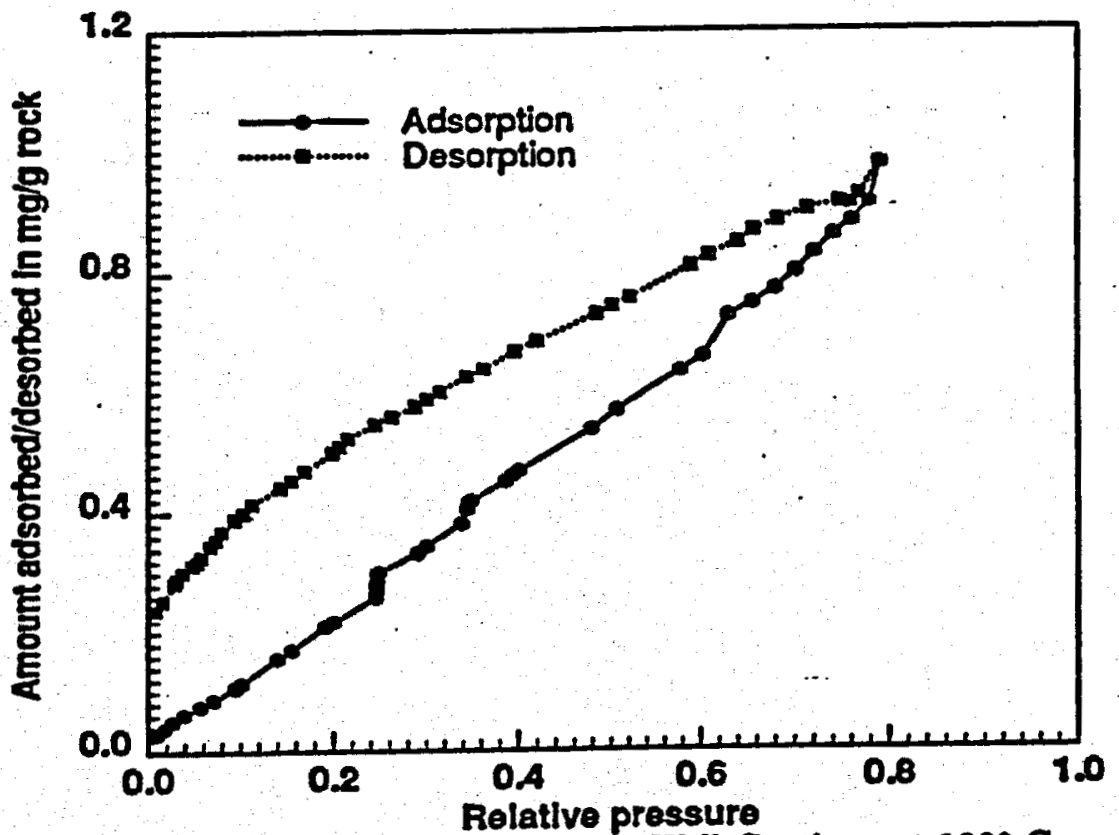

Figure 2: Isotherms on Montiverdi \#2 Well Cuttings at $120^{\circ} \mathrm{C}$ 


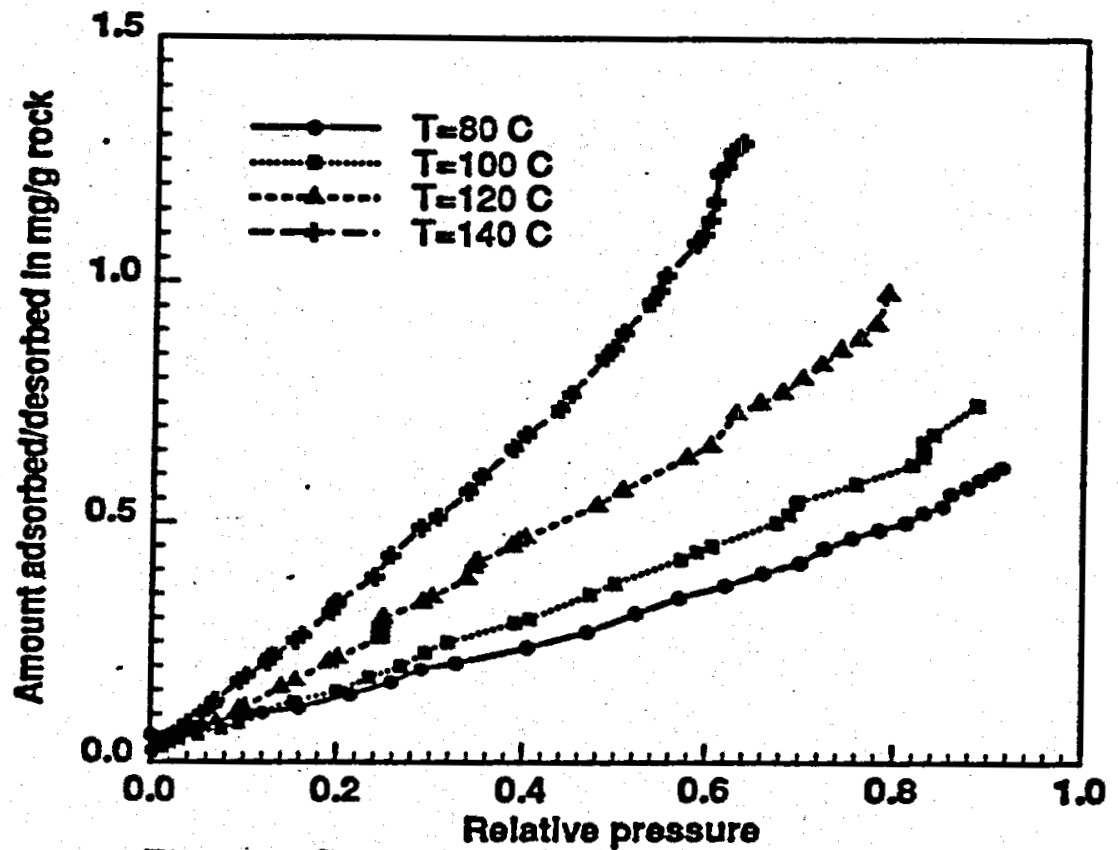

Figure 3: Comparison of Adsorption Isotherms

obtain adsorption data at near saturation pressures. Nonetheless, we expect changes in the shape of the isotherms as pressure increases further .

As described in the Annual Report (1992) on the status of the sorptometer, there was difficulty in reaching pressures higher than 40 psia with an instrument temperature of $150^{\circ} \mathrm{C}$ (the corresponding saturation pressure of water is 69 psia). PMI promised to look into the problem. However, they never came back with an answer. Thus, we decided to check the problem ourselves. First of all, we connected a water-filled sample halder to the equipment attempting to measure the saturation pressure of water at various temperatures. To our surprise, this test indicated that the instrument temperature is different from that read on the temperature controller or the system is not isothermal. A further test by inserting thermocouples into different parts of the instrument confirmed that the heat distribution in the upper part of the sorptometer is not uniform. This means that the adsorption data we have at higher relative pressures are not absolutely reliable and need to be checked. Since the sample temperatures are correct, low pressure data are valid.

Although a blower fan was present in the oystem, it never functioned. The fan appeared to be helpful in obtaining a uniform temperature, however 
the original heater/fan system was so badly designed that it was impossible to keep the fan running continnously. Thus, we had to design a new heating arrangement.

Currently, work is in progress to install a new heater. Hopefully, the new heating system will eliminate the temperature problem we have had and enable us to run adsorption/desorption tests at near saturation pressures for various temperatures. Continuous effort will be made on the development of a model to deseribe the adsorption-capillary condensation process.

\section{PHYSICS OF INJECTION OF WATER INTO VAPOR-DOMINATED GEOTHERMAL RESERVOIRS}

This project is under the direction of Research Assistant John W. Hornbrook and Prof. Roland N. Horne. The goal of this work is to better understand the physics of fluid storage and transport in geothermal reservoirs with adsorption effects present. In particular, this research is aimed at determining whether or not adsorption significantly affects the transport of fiud and heat during reinjection into vapor-dominated geothermal reservoirs.

\subsection{Introduction}

In order to design effective injection and production programs for geothermal reservoirs, the physics of the flow in the reservoirs must be understood. Geothermal reservoirs are, in general, highly fractured and heterogeneous, and the transport of fluids is influenced strongly by heat diffusion and also by adsorption or capillary retention effects.

In the Sept.1992 Quarterly Report, an overview of this topic was discussed. The current report emphasizes the research undertaken on one aspect of the topic over the last two months, specifically the perturbation expansion describing flow through porous media with adsorption present.

\subsubsection{Perturbation Expansion}

A new approach to the perturbation expansion has been taken. The method described below varies from the one described in the last quarterly report in that the entire solution has been obtained in Laplace space.

The equation describing flow in porous media is: 


$$
\frac{\partial p}{\partial t}=\frac{k}{\phi A(p) \mu_{l}} \nabla \cdot(p \nabla p)
$$

This equation may be simplified by grouping all constants and variables associated with the diffusion coefficient:

$$
\frac{\partial p}{\partial t}=A^{\prime}(p) \nabla \cdot(p \nabla p)
$$

Assuming one-dimensional flow:

$$
\frac{\partial p}{\partial t}=\frac{A^{\prime}(p)}{c_{t}} \frac{\partial^{2} p}{\partial x^{2}}
$$

where total system compressibility $\left(c_{t}\right)$ is assumed constant and may be absorbed into the nonlinear term. Boundary and initial conditions are:

1. $\mathrm{p}(0, \mathrm{t})=p_{w}$

2. $\mathrm{p}(\mathrm{L}, \mathrm{t})=p_{i}$

3. $\mathrm{p}(\mathrm{x}, 0)=p_{i}$

The linear diffusion term may be expressed as:

$$
A=A_{w}\left[1+\beta\left(p-p_{v}\right)\right]
$$

where, $A_{w}=\mathrm{A}(\mathrm{p})$ at $\mathrm{p}=p_{w}$. Dimensionless quantities may be defined as follows:

$$
\begin{aligned}
p_{d} & =\frac{p-p_{i}}{p_{w}-p_{i}} \\
x_{d} & =x / L \\
t_{d} & =\frac{A_{w} t}{L^{2}} \\
\varepsilon=\beta\left(p_{i}-p_{w}\right) & =\frac{A_{i}-A_{w}}{A_{w}} \ll 1.0
\end{aligned}
$$

After inserting dimensionless quantities, Eqn. (3) becomes:

$$
\frac{\partial p_{d}}{\partial t_{d}}=\left(1+\varepsilon p_{d}\right) \frac{\partial^{2} p_{d}}{\partial x_{d}^{2}}
$$

with boundary and initial conditions: 
1. $\mathrm{p}\left(0, t_{d}\right)=1$

2. $\mathrm{p}\left(1, t_{d}\right)=0$

3. $\mathrm{p}\left(x_{d}, 0\right)=0$

Eqn. (9) may be transformed into Laplace space:

$$
\left[s \bar{p}_{d}-p_{d}\left(x_{d}, 0\right)\right]=\left(1+\varepsilon \bar{p}_{d}\right) \frac{\partial^{2} \bar{p}_{d}}{\partial x_{d}^{2}}
$$

After making use of the initial condition, the problem in Laplace space may be written:

$$
\left(1+\varepsilon \bar{p}_{d}\right) \frac{\partial^{2} \bar{p}_{d}}{\partial x_{d}^{2}}-s \bar{p}_{d}=0
$$

with boundary conditions:

1. $\bar{p}_{d}\left(x_{d}=0\right)=1 / \mathrm{s}$

2. $\bar{p}_{d}\left(x_{d}=1\right)=0$

Eqn. (11) may be expanded in a perturbation series of the form:

$$
\bar{p}_{d}=\bar{p}_{d 0}+\varepsilon \bar{p}_{d 1}+\dot{\varepsilon}^{2} \bar{p}_{d 2}+\ldots
$$

To solve for the first term in this expansion, $\varepsilon$ is set to zero in Eqn. (11) and the resulting linear equation is solved. The first term in the perturbation expansion, $\bar{p}_{d} 0$, is:

$$
\bar{p}_{d 0}=\frac{e^{\sqrt{2}\left(1-x_{d}\right)}-e^{-\sqrt{d}\left(1-x_{d}\right)}}{s\left(e^{\sqrt{2}}-e^{-\sqrt{t}}\right.}
$$

The equation to be solved for the second term in the perturbation expansion, $\bar{p}_{d} 1$, is:

$$
\frac{\partial^{2} \bar{p}_{d 1}}{\partial x_{d}^{2}}-s \bar{p}_{d 1}=\bar{p}_{d 0} \frac{\partial^{2} \bar{p}_{d 0}}{\partial x_{d}^{2}}
$$

with boundary conditions:

1. $\bar{p}_{d 1}\left(x_{d}=0\right)=0$

2. $\bar{p}_{d 1}\left(x_{d}=1\right)=0$ 
Eqn. (14) yields the following expression for $\bar{p}_{d 1}$ :

$$
\begin{aligned}
& \bar{p}_{d 1}=\frac{e^{2 \sqrt{d}(-2+x)}}{3\left(-1+e^{-2 \sqrt{c}}\right)^{2} s^{2}}+\frac{1}{3 e^{2 \sqrt{x} x}\left(-1+e^{-2 \sqrt{c}}\right)^{2} s^{2}}+
\end{aligned}
$$

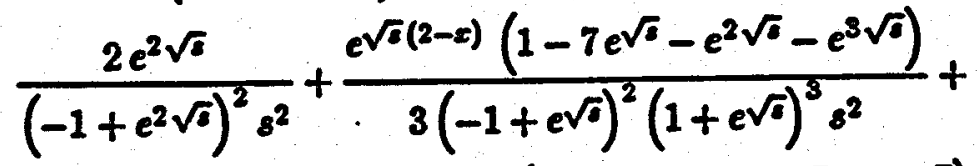

$$
\begin{aligned}
& \frac{e^{\sqrt{x} x}\left(-1-e^{\sqrt{2}}-7 e^{2 \sqrt{2}}+e^{3 \sqrt{2}}\right)}{3\left(-1+e^{\sqrt{2}}\right)^{2}(1+e \sqrt{2})^{3} s^{2}}
\end{aligned}
$$

So, the solution for pressure in Laplace space is:

$$
\begin{aligned}
& \bar{p}_{d}=\frac{e^{\sqrt{d\left(1-x_{d}\right)}}-e^{-\sqrt{d\left(1-x_{d}\right)}}}{s\left(e^{\sqrt{d}}-e^{-\sqrt{d}}\right.}+ \\
& \varepsilon\left[\frac{e^{2 \sqrt{c}(-2+x)}}{3\left(-1+e^{-2 \sqrt{x}}\right)^{2} s^{2}}+\frac{1}{3 e^{2 \sqrt{x} x}\left(-1+e^{-2 \sqrt{x}}\right)^{2} s^{2}}+\frac{2 e^{2 \sqrt{c}}}{\left(-1+e^{2 \sqrt{x}}\right)^{2} s^{2}}+\right. \\
& \left.\frac{e^{\sqrt{a}(2-x)}\left(1-7 e^{\sqrt{x}}-e^{2 \sqrt{x}}-e^{3 \sqrt{x}}\right)}{3\left(-1+e^{\sqrt{x}}\right)^{2}\left(1+e^{\sqrt{2}}\right)^{3} s^{2}}+\frac{e^{\sqrt{x} x}\left(-1-e^{\sqrt{x}}-7 e^{2 \sqrt{x}}+e^{3 \sqrt{x}}\right)}{3\left(-1+e^{\sqrt{2}}\right)^{2}\left(1+e^{\sqrt{x}}\right)^{3} s^{2}}\right]
\end{aligned}
$$

This development has only recently been achieved. In the coming quarter, the terms will be evaluated and the implications to geothermal transport determined. 


\subsection{Nomenclature}

\begin{tabular}{|c|c|c|}
\hline Variable & Description & Units \\
\hline A & Nonlinear term & dimensionless \\
\hline c & Compressibility & $1 / \mathrm{kPa}$ \\
\hline $\mathbf{k}$ & Permeability & md \\
\hline I & Characteristic length & $\mathbf{m}$ \\
\hline $\mathbf{p}$ & Pressure & bar \\
\hline$q$ & Flow rate & $\mathrm{kg} / \mathrm{s}$ or $\mathrm{m}^{3} / \mathrm{s}$ \\
\hline 8 & Laplace constant & dimensionless \\
\hline $\mathbf{t}$ & Time & B \\
\hline $\mathrm{x}$ & Adsorbed mass & $g_{a} / g_{r}$ \\
\hline $\mathbf{x}$ & Distance & \\
\hline$\beta$ & Slope of adsorption isotherm & dimensionless \\
\hline$\mu$ & Viscosity & \\
\hline$\phi$ & Porosity & dimensionless \\
\hline$\rho$ & Density & g/cc \\
\hline
\end{tabular}

\begin{tabular}{ll}
\hline Subscript & Meaning \\
$\mathbf{d}$ & Dimensionless \\
$\mathbf{i}$ & initial \\
$\mathbf{l}$ & Liquid \\
$\mathbf{p}$ & Pressure or Constant pressure \\
$\mathbf{I}$ & Rock \\
$\mathbf{t}$ & Total \\
$\mathbf{w}$ & wellbore \\
$\mathbf{\infty}$ & Infinity
\end{tabular}

\section{EARTH-TIDE-EFFECTS ON DOWNHOLE PRESSURES}

This project is being undertaken by Research Assistant Edgar Dias under the guidance of Prof. Henry J.Ramey, Jr. The aim of the project is to develop a method to derive reservoir parameters by utilizing the phase-shifts observed between exciting tidal forces, and the downhole pressure response to these forces. 


\subsection{Derivation of Phase shift expression}

Using an element of the earth, we derived an expression relating the incremental pressure and reservoir parameters. This differential equation contained a general expression of the stress function due to earth- tides.

$$
\frac{K}{\rho g} \nabla^{2} \sigma=\left(\alpha+\phi \beta^{\prime}\right) \frac{\partial \sigma}{\partial t}+\alpha F(t, z)+\alpha C \exp i \omega t
$$

where :

$$
\alpha=\frac{1}{\lambda+\mu}
$$

$F(t, z)$ is a constant of integration

\subsection{Mathematical Description}

We model the reservoir as circular disk. The outer radius is $R$ and the well of radius $a$ is at the center of the disk. The reservoir thickness is $h$, and the top of the reservoir is at a depth $H$. For convenience we position the origin of the frame of reference at the center of the circular disk, $h$ is small relative to $B$, the overburden height.

Rewriting the mathematical definition of the problem, we have the governing equation of flow:

$$
\frac{K}{\rho g} \nabla^{2} \sigma=\left(\alpha+\phi \beta^{\prime}\right) \frac{\partial \sigma}{\partial t}+\alpha F(t, z)+\alpha C \exp i \omega t
$$

where:

$$
\alpha=\frac{1}{\lambda+\mu}
$$

$F(t, z)$ is a constant of integration

Assuming impermeable boundaries on the top and bottom, we get: at $z= \pm \frac{h}{2}$ :

$$
\frac{\partial \sigma}{\partial z}=0
$$

and an oscillating flow at the inner boundary

at $r=a$ :

$$
\frac{\partial \sigma}{\partial r}=\frac{Q \rho g}{2 \pi K a h}
$$


for $t>0$

and an outer impermeable boundary

at $\boldsymbol{r}=\boldsymbol{R}$ :

$$
\frac{\partial \sigma}{\partial r}=0
$$

The initial conditions assumed are: at $t=0: C=0$; and $F=0$

let $Q=Q_{0} \exp i(\omega t+\psi):$ where $\psi$ is the phase shift and where $\omega$ is the tidal frequency being considered.

The governing equation is nonlinear due to the $F(t, z)$ and $C$ functions on the right side. In order to solve it we first solve the homogeneous equation and expand the nonhomogenous terms as an infinite series of the eigenfunctions of the homogenous problem.

The homogenous governing equation may written as:

$$
\frac{K}{\rho g\left(\alpha+\phi \beta^{\prime}\right)} \nabla^{2} \sigma=\frac{\partial \sigma}{\partial t}
$$

This may be written as:

$$
\zeta \nabla^{2} \sigma=\frac{\partial \sigma}{\partial t}
$$

where $\zeta$ includes the constant terms, with the original boundary conditions, and the initial conditions.

The initial conditions indicate that earth-tidal effects started at time $t=0$. This leads us to a transient response and a steady-state response. We will concentrate on the steady-state response, which contains the desired information.

So, let the solution be denoted as:

$$
\sigma=\sigma_{t}(r, z, t)+\sigma_{a}(r, z, t)
$$

where $\sigma_{t}$ is the transient solution, and $\sigma_{a}$ is the steady-state solution.

We wiil write the steady-state colution as:

$$
\sigma_{s}=\sigma_{o}(r, z) \exp i(\omega t+\psi)
$$

The problem subdivides into transient and steady-state parts as follows: 


\section{Steady-State Problem:}

$$
\begin{array}{r}
\left\langle\nabla^{2} \sigma_{s}=\frac{\partial \sigma_{s}}{\partial t}\right. \\
\sigma_{s}(z, r, t)=\sigma_{s}(r, z) \exp i(\omega t+\psi)
\end{array}
$$

with the boundary conditions:

$$
\frac{\partial \sigma_{a}}{\partial z}=0
$$

at $z= \pm \frac{h}{2}$ for $a<r<R$

$$
\frac{\partial \sigma_{s}}{\partial r}(a, z, t)=Q^{\prime} \exp i(\omega t+\psi)
$$

for $t>0$ and where: $Q^{\prime}=\frac{Q_{0} \rho g}{2 \pi K a h}$

$$
\frac{\partial \sigma_{a}}{\partial r}(R, z, t)=0
$$

for $\frac{-h}{2}<z<\frac{h}{2}$

Transient State Problem:

$$
\zeta \nabla^{2} \sigma_{t}=\frac{\partial \sigma_{t}}{\partial t}
$$

for $a<r<R$ and $\frac{-h}{2}<z<\frac{h}{2}$, and $t>0$

$$
\frac{\partial \sigma_{t}}{\partial z}=0
$$

atz $= \pm \frac{h}{2}$

$$
\frac{\partial \sigma_{t}}{\partial r}=0
$$

at $r=R$

$$
\frac{\partial \sigma_{t}}{\partial r}=0
$$


at $r=a$

and

$$
\sigma_{t}(r, z, 0)=-\sigma_{\imath}(r, z, 0)
$$

For the solution to the steady-state problem, we have:

$$
\sigma_{s}(r, z, t)=\sigma_{s}(r, z) \exp i(\omega t+\psi)
$$

substituting in the governing equation:

$$
\zeta \nabla^{2} \sigma_{2}=\frac{\partial \sigma_{2}}{\partial t}
$$

and differentiating both sides we get:

$$
\zeta \nabla^{2} \sigma_{s}(r, z)=i \omega \sigma_{s}(r, z)
$$

where $\sigma_{s}(r, z)=R(r) Z(z)$

Then using cylindrical coordinates and substituting, we get by separation of variables

$$
\frac{\left(r R^{\prime}\right)^{\prime}}{r} Z+R Z^{\prime \prime}=\frac{i \omega}{\zeta} R Z
$$

dividing through by $\mathrm{RZ}$ we get:

$$
\frac{\left(r R^{\prime}\right)^{\prime}}{r R}-\frac{\dot{\omega} \omega}{\zeta}=\frac{-Z^{\prime \prime}}{Z}=\beta^{2}
$$

i.e.:

$$
Z^{\prime \prime}+\beta^{2} Z=0
$$

and

$$
\left(r R^{\prime}\right)^{\prime}-r R\left(\beta^{2}+\frac{i \omega}{\zeta}\right)=0
$$

now putting

$$
\lambda^{2}=\beta^{2}+\frac{i \omega}{\zeta}
$$


we have:

$$
\left(r R^{\prime}\right)^{\prime}-r R \lambda^{2}=0
$$

the general solution to these two equations may be written as:

$$
Z=C_{1} \sin (\beta Z)+C_{2} \cos (\beta Z)
$$

and

$$
R=C_{3} I_{0}(\lambda r)+C_{4} K_{0}(\lambda r)
$$

Substituting the boundary conditions at $z= \pm \frac{h}{2}$ we get:

$$
Z_{n}=C_{n} \cos \left\{\frac{(2 n-1) \pi\left(z-\frac{h}{2}\right)}{h}\right\}
$$

for

$$
n=1,2, \ldots
$$

and:

$$
R_{n}=C_{4 n}\left\{\frac{K_{1}\left(\lambda_{n} R\right)}{I_{1}\left(\lambda_{n} R\right)} I_{0}\left(\lambda_{n} r\right)+K_{0}\left(\lambda_{n} r\right)\right\}
$$

These eigenfunctions are orthogonal and we can write:

$$
\sigma_{s n}(r, z, t)=\sum_{i=1}^{n} R_{n}(r) Z_{n}(z) \exp i \omega t
$$

Now we go back to the nonlinear equation and express the nonlinear terms as infinite series of the ejgenfunctions derived above.

Coming back to our original governing equation:

$$
\zeta \nabla^{2} \sigma=\frac{\partial \sigma}{\partial t}+\frac{\alpha}{\alpha+\phi \beta^{\prime}} F(t, z)+\frac{\alpha}{\alpha+\phi \beta^{\prime}} C \exp i \omega t
$$

where:

$$
\alpha=\frac{1}{\lambda+\mu}
$$

$\sigma$ will be written as $\sigma_{a}$, which denotes an average value of $\sigma$ over $h$. This equation may be written as:

$$
\zeta\left\{\frac{\partial^{2} \sigma}{\partial r^{2}}+\frac{1}{r} \frac{\partial \sigma}{\partial r}+\frac{\partial^{2} \sigma}{\partial z^{2}}\right\}=\frac{\partial \sigma}{\partial t}+\chi F(t, z)+\chi C \exp i \omega t
$$


where:

$$
x=\frac{\alpha}{\alpha+\phi \beta^{\prime}}
$$

and $u$ sing average values over $h$ we get by integrating from $z=-\frac{h}{2}$ to $z=\frac{h}{2}$ :

$$
\zeta\left\{\frac{\partial^{2} \sigma_{a}}{\partial r^{2}}+\frac{1}{r} \frac{\partial \sigma_{a}}{\partial r}+\left.\frac{\partial \sigma}{\partial z}\right|_{\frac{h}{z}}-\left.\frac{\partial \sigma}{\partial z}\right|_{\frac{-h}{2}}\right\}=\frac{\partial \sigma_{a}}{\partial t}+\chi F_{a}(t)+\chi C_{a} \exp i \omega t
$$

Using:

$$
\left.\frac{\partial \sigma}{\partial z}\right|_{-h / 2}=0
$$

and

$$
\left.\frac{\partial \sigma}{\partial z}\right|_{i / 2}=0
$$

we get :

$$
\zeta\left\{\frac{\partial^{2} \sigma_{a}}{\partial r^{2}}+\frac{1}{r} \frac{\partial \sigma_{a}}{\partial r}\right\}=\frac{\partial \sigma_{a}}{\partial t}+\chi F_{a}(t)+\chi C_{a} \exp i \omega t
$$

Now expressing the right hand side as an infinite series of the eigenvalues obtained from the homogenous equations, we get:

$$
\chi F_{e}(t)+\chi C_{a} \exp i \omega t=\sum_{i=1}^{n} q_{n}(t) R_{n}(r)
$$

where $R_{n}(r)$ is the eigenfunction derived earlier. Then by orthogonality we can find $q_{n}(t)$ by integrating between $r=a$, to $r=R$

$$
q_{m}(t)=\int_{a}^{R}\left\{\chi F_{a}(t)+\chi C_{a} \exp i \omega t\right\} R_{m}(r) \partial r
$$

Substituting the derived values in the initial condition at $r=a$ will allow the extraction of $\psi$ in terms of known reservoir parameters.

As seen from the procedure above, we will need to obtain characteristic expression which describe $F(t, z)$ and $C$ realistically in order to obtain the value for $\psi$. This will involve an analysis of soil mechanics and a simplifcation to obtain descriptions which are realistic but easy to manipulate. 


\subsection{Data Processing}

While the first part of this project, as described in the previous section, concerns itself with obtaining a mathematical expression for the phase shift in terms of reservoir parameters, we have also started work on an actual set of data which showed the presence of earth-tides.

The aim of the data processing is the following:

1. To write a program which can calculate theoretical gravity variations due to earth-tides at the location of data acquisition.

2. To design a filter using Fourier analysis which can remove noise and barometric pressure changes from field data.

3. To compare the theoretical data with the filtered data and determine quantitatively phase shifts shown.

The present status of the data processing part is as follows. The data from Palm Valley which is being processed has been passed through a fast Fourier transform operation using the MATLAB program. The power spectrum of the raw signal shows peaks in the low frequency range.

The program to obtain theoretical data will use the equation of the earth-tide potential as derived by Melchior.

$$
\begin{aligned}
3.4 & \text { Nomenclature } \\
r_{w} & =\text { Radius of well bore } \\
T & =\text { Transmissivity of the reservoir } \\
e & =\text { Volume strain } \\
S_{r} & =\text { Fluid Saturation } \\
p_{b} & =\text { Bull density } \\
K & =\text { Permeability coefficient } \\
v_{A} & =\text { Displacement velocity of the solid medium } \\
u_{A} & =\text { Displacement vector of the solid material } \\
\phi & =\text { Porosity } \\
\sigma & =\text { Incremental stress }
\end{aligned}
$$




\section{INJECTION OPTIMIZATION AT THE GEY- SERS}

This is a new project this quarter and is being undertaken by Research Assistant Zosimo Aunzo and Prof. Roland Horne.

The purpose of this work is to quantify the effects and optimize injection at the Geysers Geothermal Field.

The study will begin by collating all information regarding the injection and production history of the Geyser's Geothermal Field using the production database established by LBL. The data would be analyzed to determine the effect of injection into the reservoir. This would involve correlating injection with the production history of the field. Once a correlation has been established, we will attempt to describe the physics behind the field response.

The bullk of the work that will be done on the earlier part of the project will be on data collection, integration and analysis of production and injection history at the Geysers. After this is done, the field response to injection will be analyzed using techniques similar to those used earlier in analyzing the reinjection strategy of the Palinpinon Geothermal Field, Philippines.

\section{EFFECTS OF SALINITY IN ADSORPTION EXPERIMENTS}

This is another new project starting this quarter, and will be performed by Research Assistant Steve Palar and Profs. Roland N. Horne and Henry J. Ramey, Jr.

Past experiments of adsorption used only pure water. This project will analyze the effect of dissolved salts on adsorption using cores which have been previously soaked with brine. In addition, the role of temperature on transient pressure will be investigated.

Salinity may be quite significant, especially during reinjection. The reinjected water may contain salts and the subsequent effect of salinity is to reduce the vapor pressure. The thermodynamics of heat transfer and the production of steam may change with the introduction of increasing salt concentrations.

The objective of the experiment is to establish a relationship between the transient pressure drop after salts have been introduced onto the surfaces of geothermal cores. 
The experiment will utilize the existing laboratory equipment, on loan from the USGS. Cores from the Geysers will be used.

\section{INTERPRETING MULTIWELL PRESSURE DATA FROM OHAAKI}

This investigation is being performed by Research Assistant, Xianfa Deng, and Prof. Roland N. Horne. The purpose of the study is to examine means of estimating reservoir heterogeneity using pressure transient and tracer tests. In the present stage of the project, we have undertaken a field study to reinterpret data from the Ohaaki geothermal using nonlinear regression by matching the pressure data from multiple interference tests, to see how reservoir beterogeneity affects the result.

\subsection{Introduction}

Using interference testing to evaluate reservoir heterogeneity and average transmissivity and storativity is a convenient and common method in geothermal fields. Twelve interference tests have been performed at Ohaaki geothermal field between six well pairs. Leaver et al [1988] analyzed those testing in an effort to identify a no-flow linear boundary using the inference ellipse method proposed by Vela [1977]. Leaver et al matched the pressure data only one pair at a time. The results are dominated by the local transmissivity and storativity between or around the two wells, so each matching gives a local average different from another. It is hard to say which estimated permeability value can be used as an average for the whole reservoir. Furthermore, by the inference ellipse method, there is considerable flexibility in deciding the location of linear boundary, since each two pairs of data give two ellipses which are sufficient to estimate a location of a linear boundary. A better way would be to match all the data pairs simultaneously, hopefully giving more consistent results.

\subsection{Matching by Nonlinear Regression}

The parameters matched are bulk transmissivity, $k h / \mu$, storativity, $\phi c_{t} h$, the location of the linear boundary (two variables needed for identification), and the initial pressures of each active well. There are twelve sets of interference pressure data available, which means we have sixteen parameters to be matched. The theoretical drawdown and buildup curves used in the 
analysis were similar to those developed by Eiper [1985], except that the linear boundary effect was included in the curves. To make this possible, a Cartesian coordinate is defined with $B R 20$ as the origin, 60 the location of each well is represented by a pair of numbers $(x, y)$ as follows:

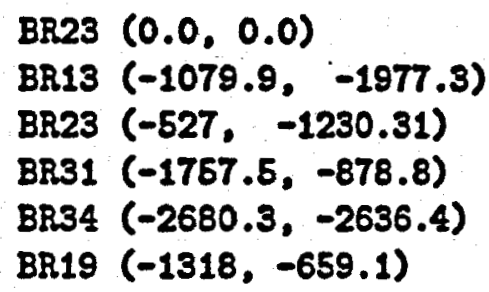

We represent the linear boundary by another pair of $(x, y)$ coordinates representing the point on the boundary which is nearest to the origin of our Cartesian coordinates. The algorithm used for this nonlinear regression problem is similar to the Gauss-Newton method except some corrections on the damping factor.

The results from Leaver et al [1988] are presented in Figure 4 and listed as follows (same units for all data below):

$k h=250(d-f t) \phi c_{t} h=0.008(f t / p s i * 1 e 4) x_{b}=-1494(f t) y_{b}=2724(f t)$

This interpretation gives an average residual of 1.999 psi per point (there are 1969 data points for all 12 wells). If we start from this result as an initial guess, after 11 iterations the algorithm finds a solution as shown in Figure 5:

$$
k h=547.92 \quad \phi c_{h} h=0.0119 \quad x_{b}=-1981.07 \quad \nu_{b}=-1631.12
$$

which gives an average residual of $1.4366 \mathrm{psi}$ per point. Notice that tests $B 7$ and $B 8$ are worse than before, since they have less points and contribute less to the residual.

If we add the twelve initial pressures of the active wells as parameters, we can reduce the residual to 0.97 psi per point as shown in Figure 6 with estimated values as follows:

$$
\begin{array}{ccc}
k h=584.96 \quad \phi c_{i} h=0.00473 \quad x_{b}=-3031.12 & y_{b}=-2076.63 \\
p_{i}^{B 1}=-7.11 & p_{i}^{B 2}=-10.50 \quad p_{i}^{B 3}=-53.15 \quad p_{i}^{B 4}=14.30 \\
p_{i}^{B 6}=-9.13 \quad p_{i}^{B 7}=-117.83 \quad p_{i}^{B 8}=-67.89 \quad p_{i}^{B 9}=297.20
\end{array}
$$




$$
p_{i}^{B 10}=-32.76 p_{i}^{C 1}=3.36 p_{i}^{C 2}=-24.25 p_{i}^{C 3}=-6.17
$$

From Figure 6, we see that four sets of data $B 6, B 7, B 8$ and $B 9$ are not well-behaved. Excluding these four sets, the match was repreated with the remaining eight sets of pressure data. Figure 7 is the result withont initial pressures as parameters but with weights to emphasize the early data. The result is

$$
k h=734.75 \quad \phi c_{t} h=0.0052 \quad x_{b}=-1663.09 \quad y_{b}=-2883.21
$$

With initial pressures as parameters without emphasis on early data, we have (Figure 8):

$$
\begin{aligned}
& k h=659.31 \quad \phi c_{t} h=0.0032 \quad x_{b}=-5067.12 \quad y_{b}=18.74 \\
& p_{i}^{B 1}=-4.88 \quad p_{i}^{B 2}=-2.75 \quad p_{i}^{B 3}=-54.73 \quad p_{i}^{B 4}=14.38 \\
& p_{i}^{B 10}=-29.48 \quad p_{i}^{C 1}=12.12 \quad p_{i}^{C 2}=-14.24 \quad p_{i}^{C 3}=14.83
\end{aligned}
$$

With weights and initial pressures as parameters, we end up with

$$
\begin{array}{cccc}
k h=630.98 & \phi c_{t} h=0.0033 & x_{b}=-1506.85 & y_{b}=2749.59 \\
p_{i}^{B 1}=-4.41 & p_{i}^{B 2}=0.379 & p_{i}^{B 3}=-61.96 & p_{i}^{B 1}=17.10 \\
p_{i}^{B 10}=-34.01 & p_{i}^{C 1}=5.96 & p_{i}^{C 2}=-28.81 & p_{i}^{C 3}=17.35
\end{array}
$$

as shown in Figure 9.

All the data above are calculated with $h=2297(f t)$ and $\mu=0.34(c p)$.

Notice that in $B 3$ of Figure 7, the calculated type curve is parallel and above the actual data and we could not shift it vertically without sacrificing the other matches. All the data matches affect each other here. When initial pressure is allowed to vary, the actual data of test $B 3$ are increased by the same amount, resulting in a big jump in the early data as shown in the log-log graphs in Figures 7 and 8.

It is also worth mentioning that the location of the linear boundary is sensitive to the sets of data used. It is likely that there is a northwest/southeast trend of faults, and we always have a higher average permeability than 110 (md) as suggested by Leaver et al [1988].

Based on these results, it seems likely that the data cannot be interpreted adequately in terms of a single average permeability, nor can the single linear fault model be used with much confidence. As a starting point of this work, this set of field examples demonstrates the need for the consideration of heterogeneity, which is the primary focus of the project. 
Type-curve Match for Multi-well Pressure Data of Ohaaki Geothermal Fleld

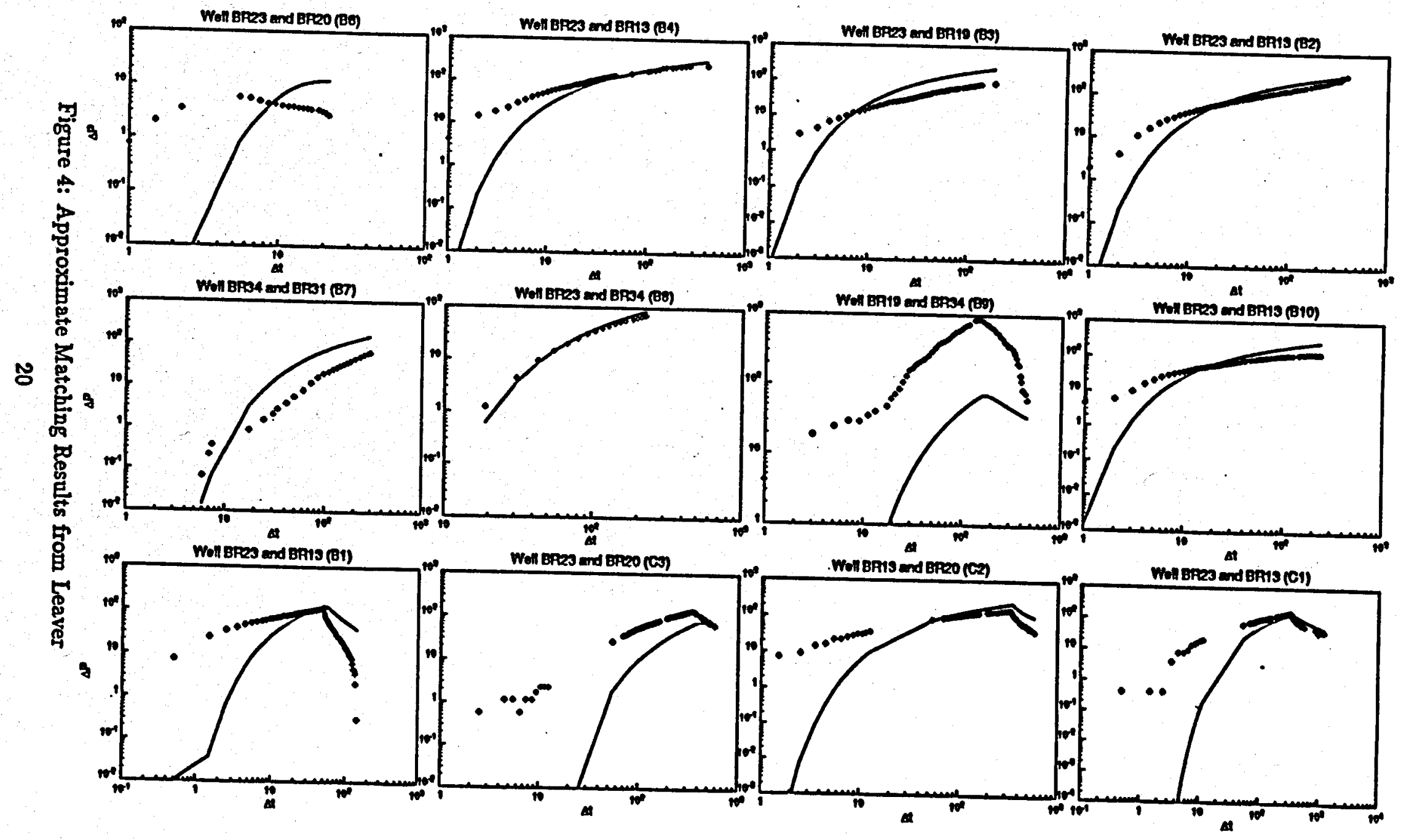


Type-curve Match for Multi-well Pressure Data of Ohaakl Geothermal Field

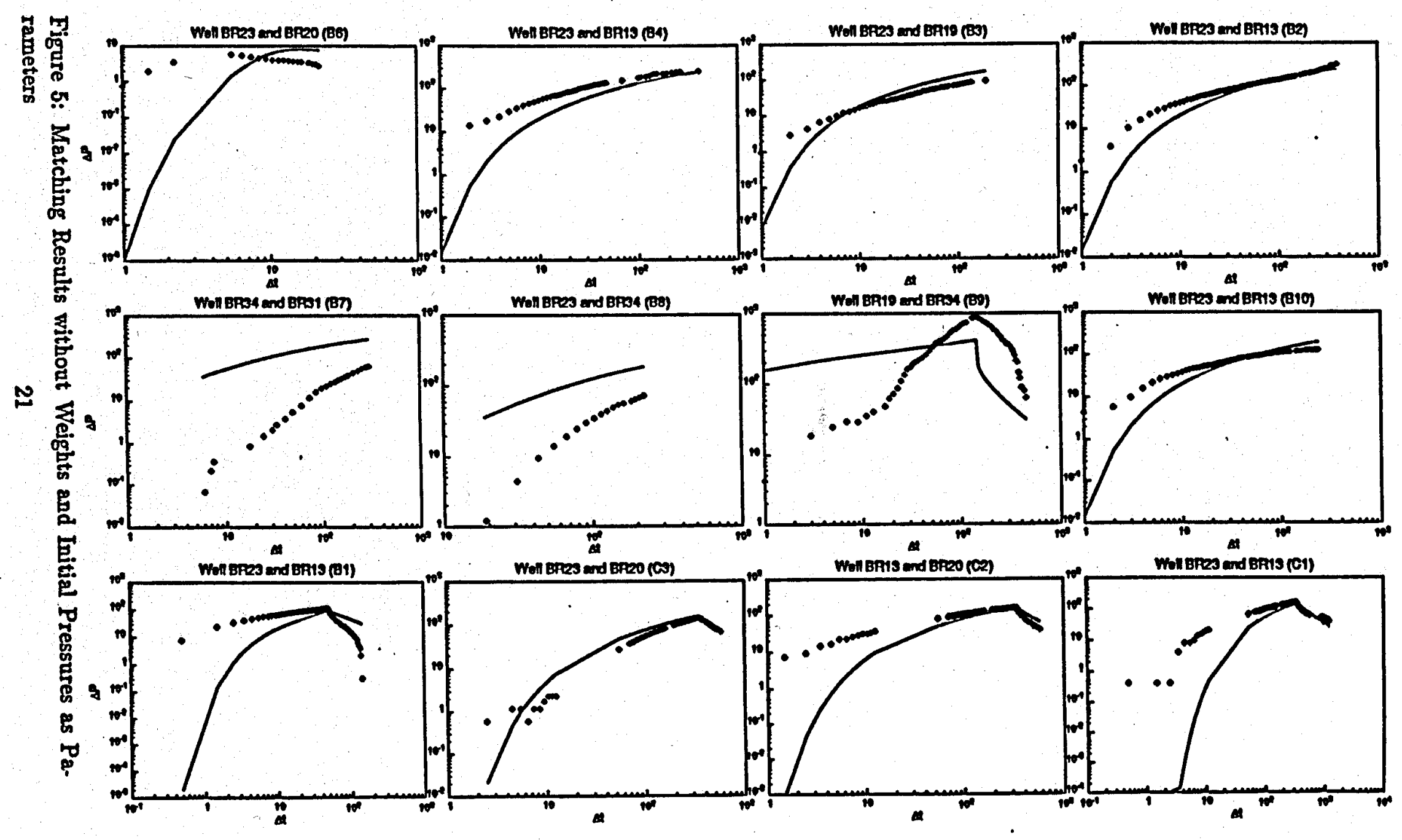


Type-curve Match for Multi-well Pressure Data of Ohaakl Geothermal Feld

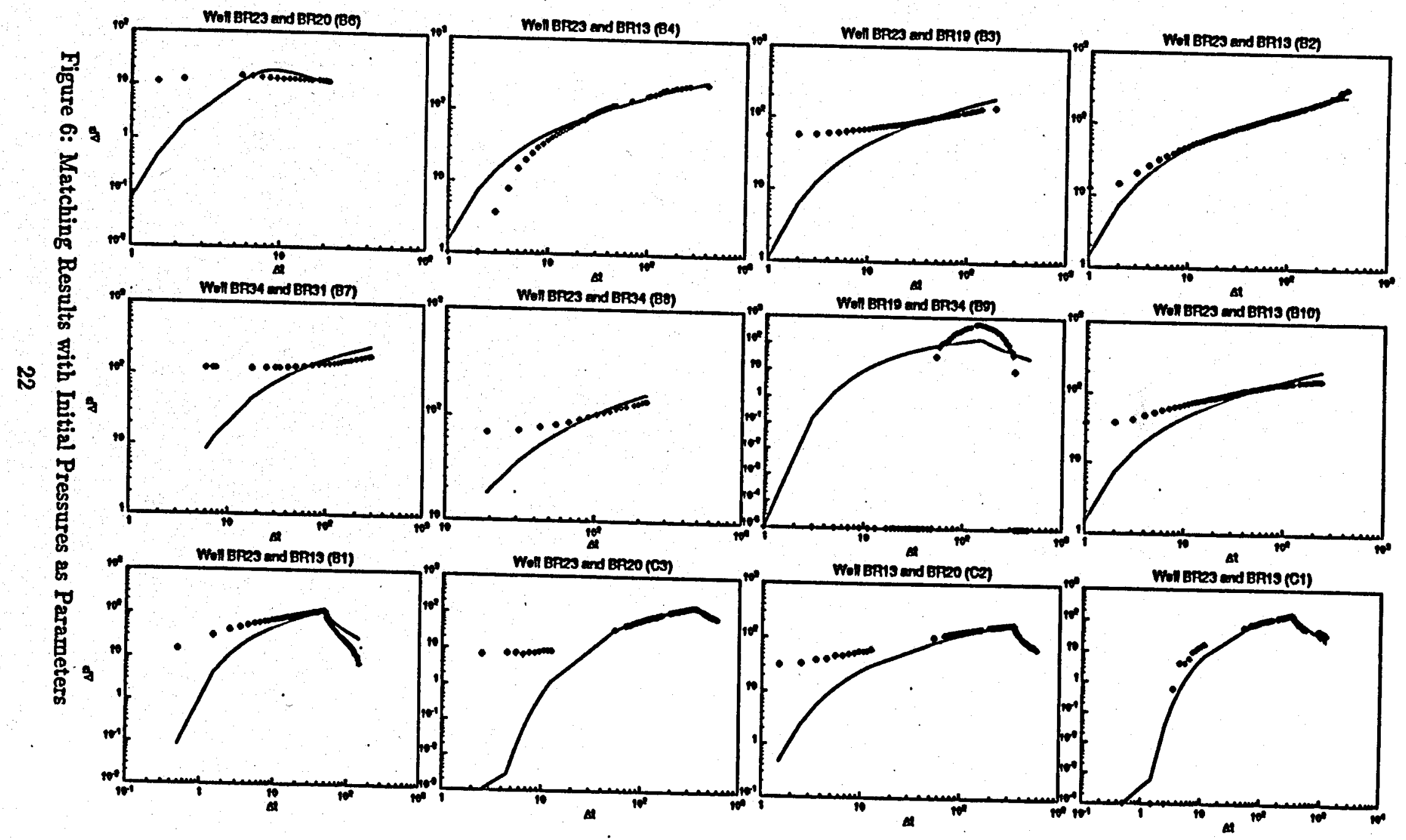


Type-curve Match for Multi-well Pressure Data of Ohaakj Geothermal Field
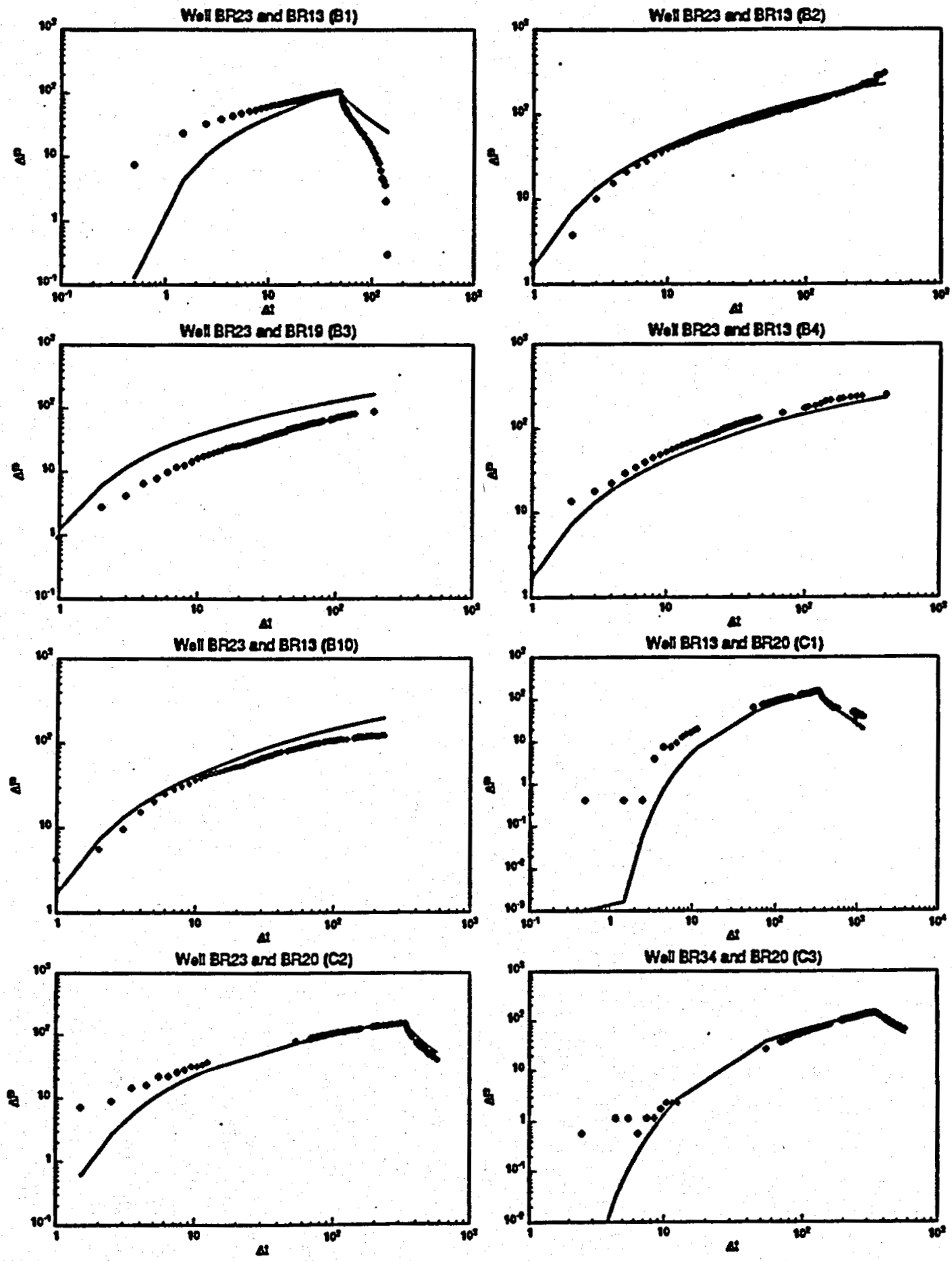

Figure 7: Matching Results with Weights Emphasizing Early Data 
Type-curve Match for Multi-well Pressure Data of OhaakJ Geothermal Field
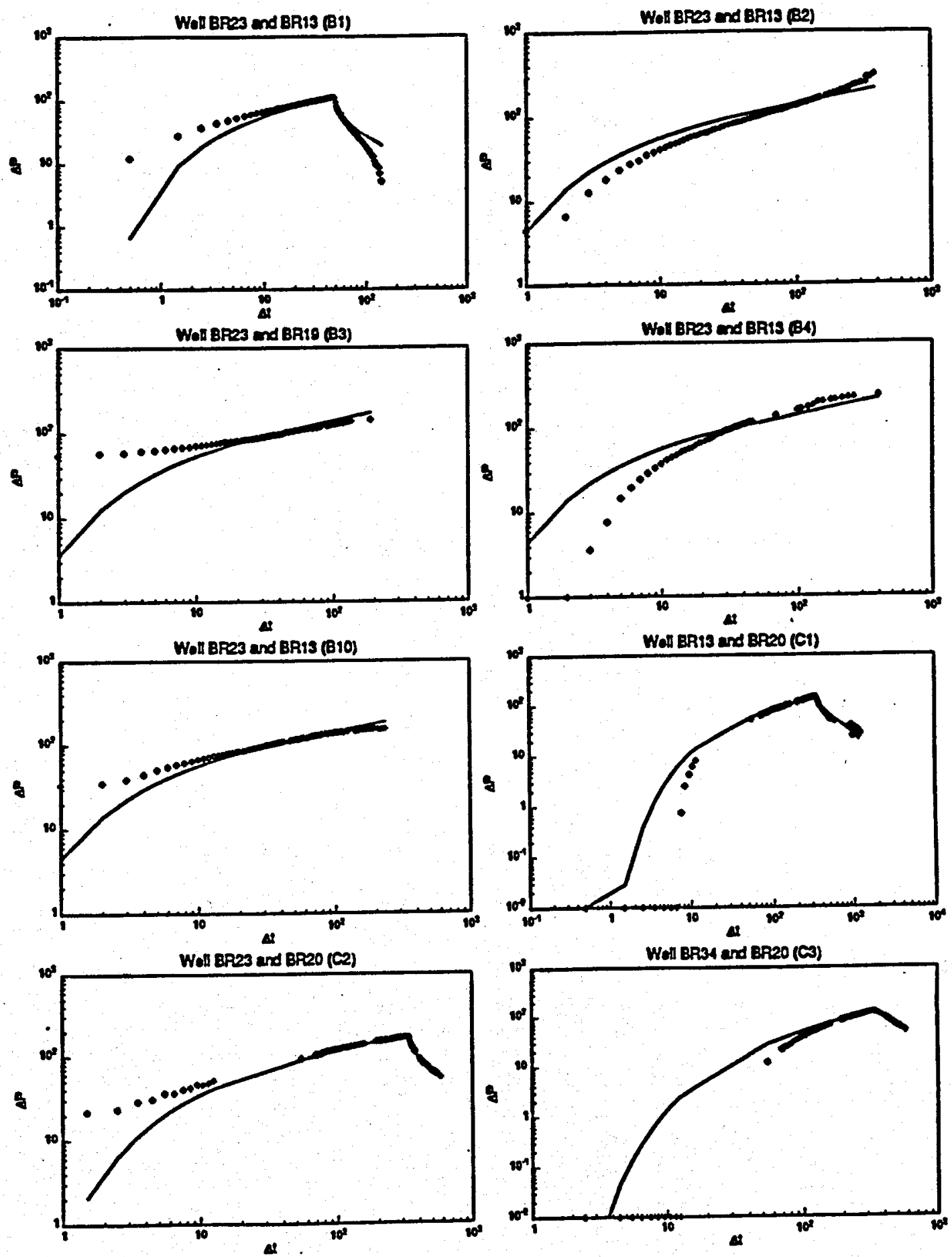

Figure 8: Matching Results with Initial Pressures as Parameters 
Type-curve Match for Multi-well Pressure Data of Ohaaki Geothermal Field
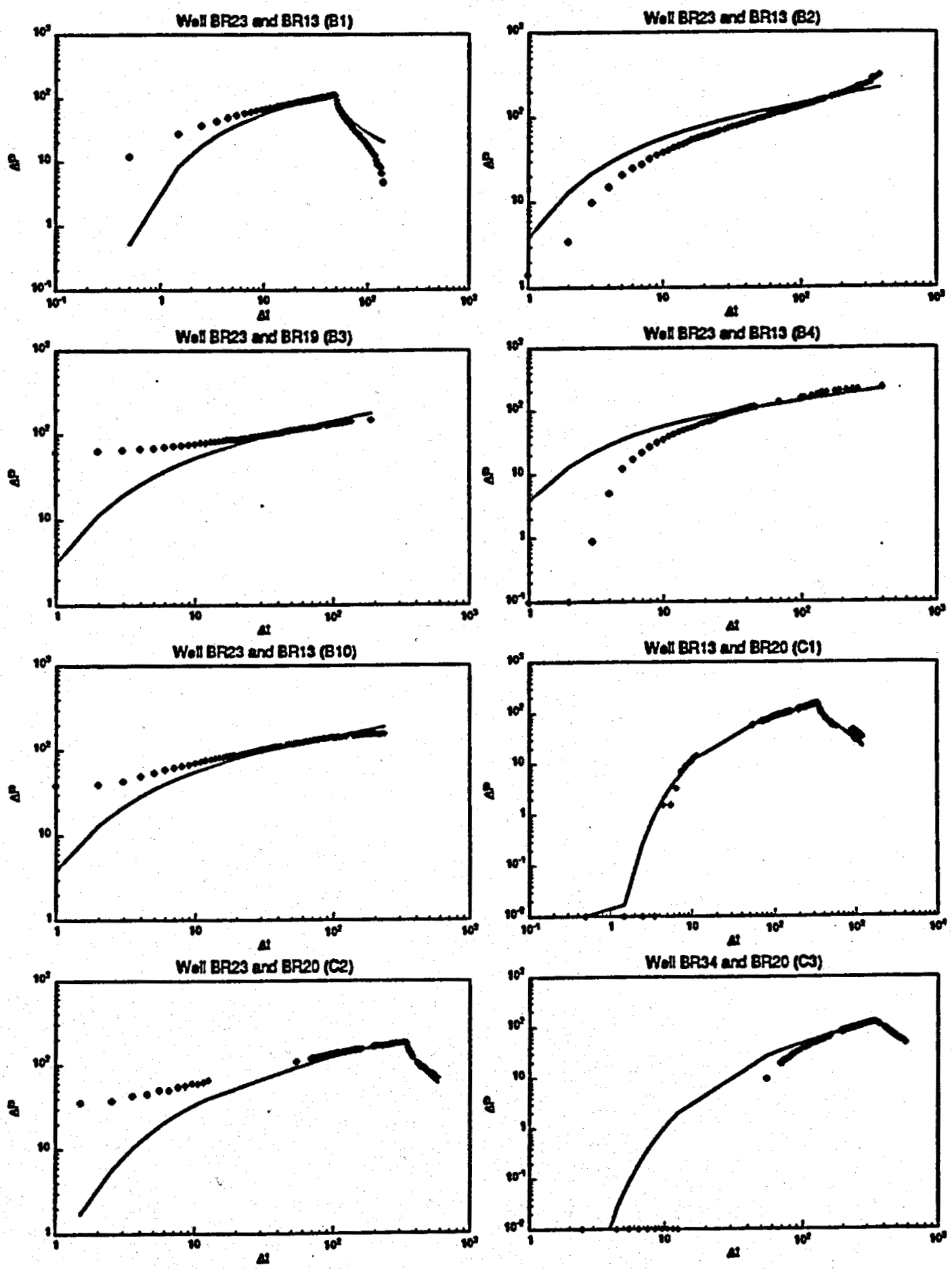

Figure 9: Matching Results with Weights and Initial Pressures as Parameters 


\section{ESTIMATION OF ADSORPTION PARAME- TERS FROM TRANSIENT EXPERIMENTS}

This project is being performed by Research Assistant Ming Qi, together with Profs. Roland N. Horne and Henry J. Ramey, Jr..

During the quarter, we analyzed eight sets of water vapor pressure transient experiment data obtained during the previous quarter (July, August and September, 1992).

\subsection{Estimation of the Sorption Isotherm}

As mentioned in the previous report, all runs were made under the same conditions that Michael Harr used in 1991 and comparison with Harr's results Harr (1991) were made and discnssed. With the newly measured data, we estimated the adsorption isotherm by nonlinear regression.

We first provide a pair of guessed values for $A$ and $B$ in the Langmuir adsorption isotherm and then run the one-dimensional steam flow simulator developed by Nghiem and Ramey (1991) to calculate the steam pressure changing with time. The pressure is matched to the experimental result using nonlinear regression. Having obtained estimates of $A$ and $B$ we can calculate the Langmuir isotherm from Eqn. 30:

$$
X=\frac{p / p_{\text {sat }}}{A+\bar{B} p / p_{\text {sat }}}
$$

The results of estimated isotherms are shown in Figure 10 through Figure 17.

\subsection{Discussion}

There are many factors affecting the result of the transient flow experiment and consequently the estimated isotherm. These factors include the temperature, the permeability, the porosity, partical size distribution, rock type, etc. The effects of permeability and porosity are discussed below.

Also the validity of the estimation procedure can be checked by comparing the results obtained by regression with the results obtained from other experiments. There are not many results available for the comparison. One useful set of comparable data is the isotherm measured from the equilibrium experiment by Shubo Shang, as described earlier in Section 1 of this report. 


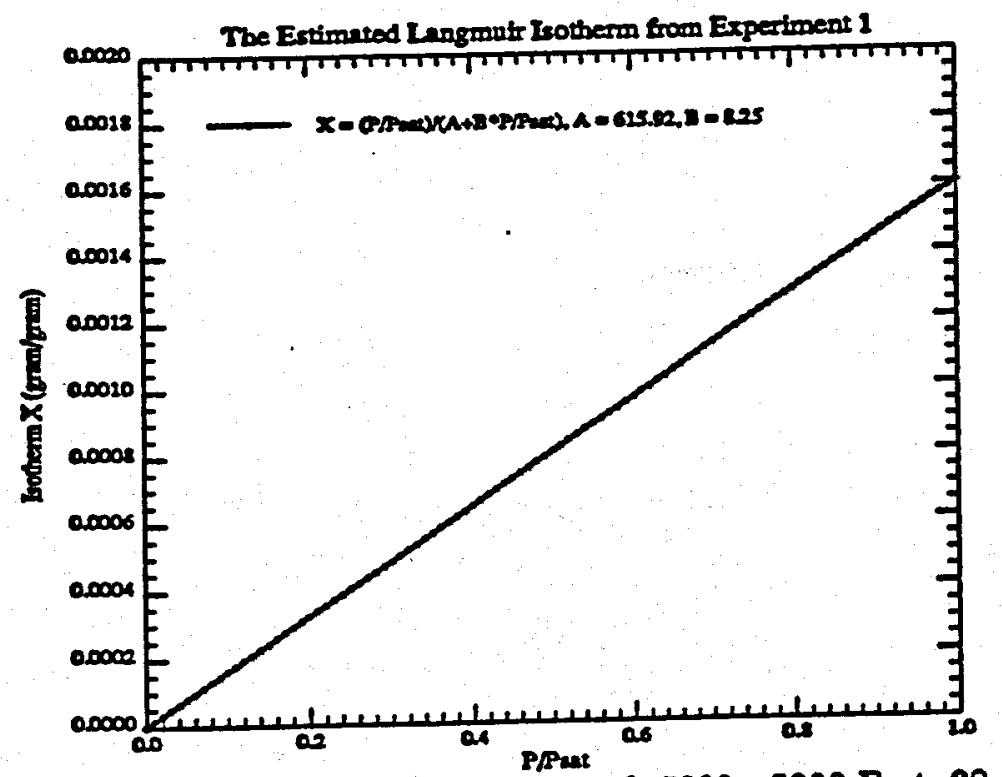

Figure 10: Geysers Unknown Well, Depth 5000 - 5200 Feet, 28-150 Mesh

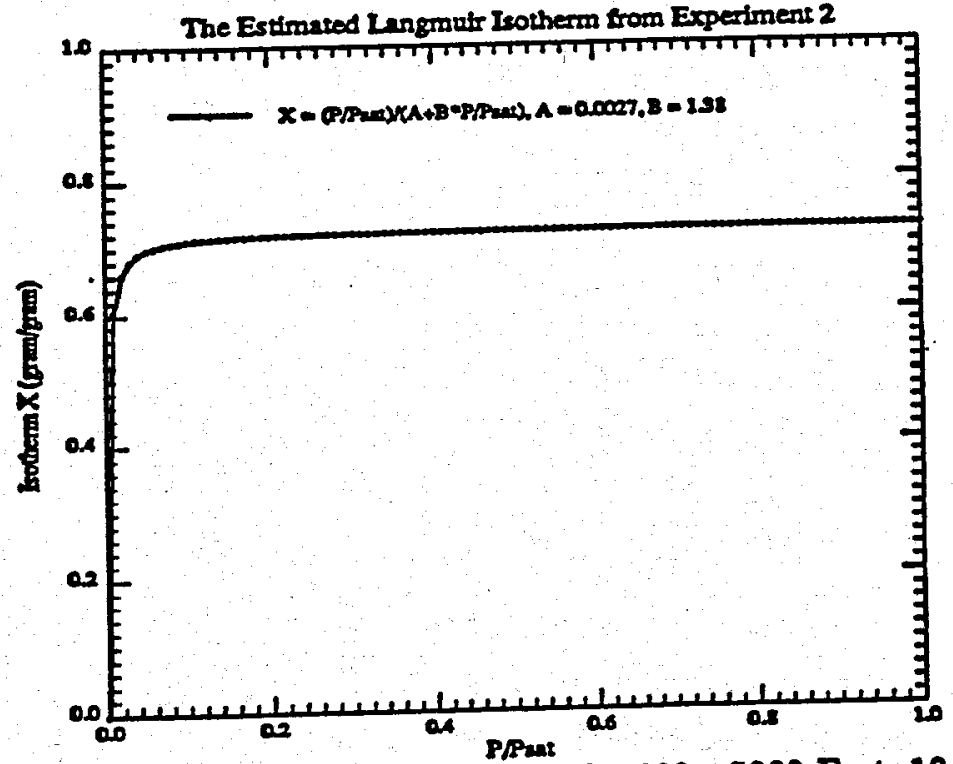

Figure 11: Geysers Well OF52-11, Depth 5000 - 5200 Feet, 10-150 Mesh 


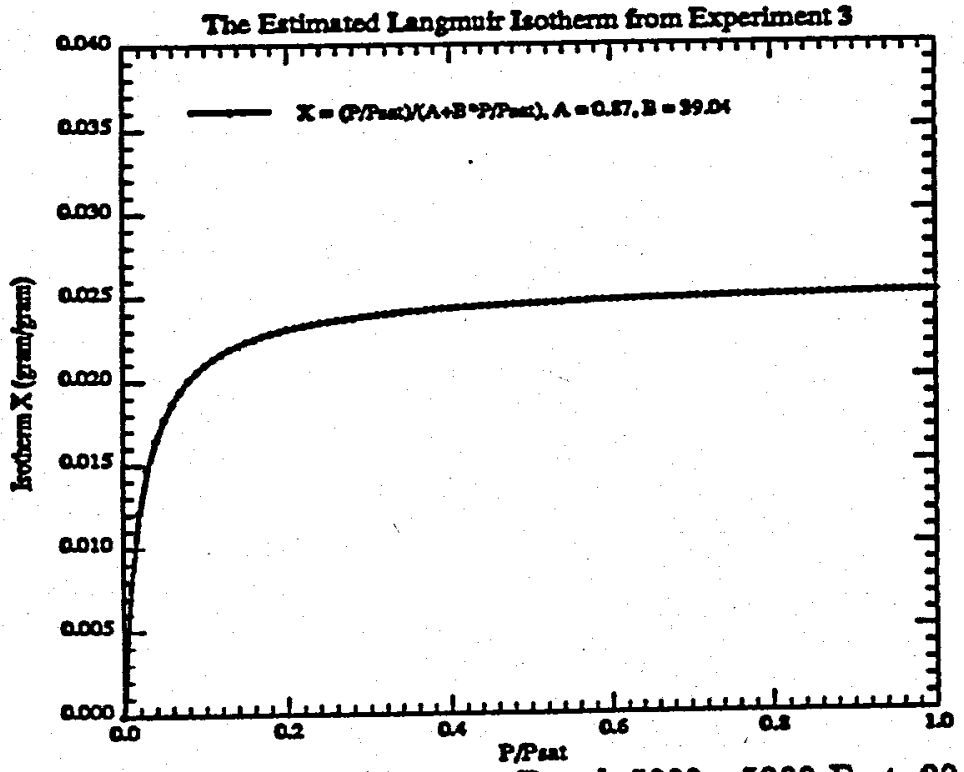

Figure 12: Geysers Well OF52-11, Depth 5000 - 5200 Feet, 20-150 Mesh

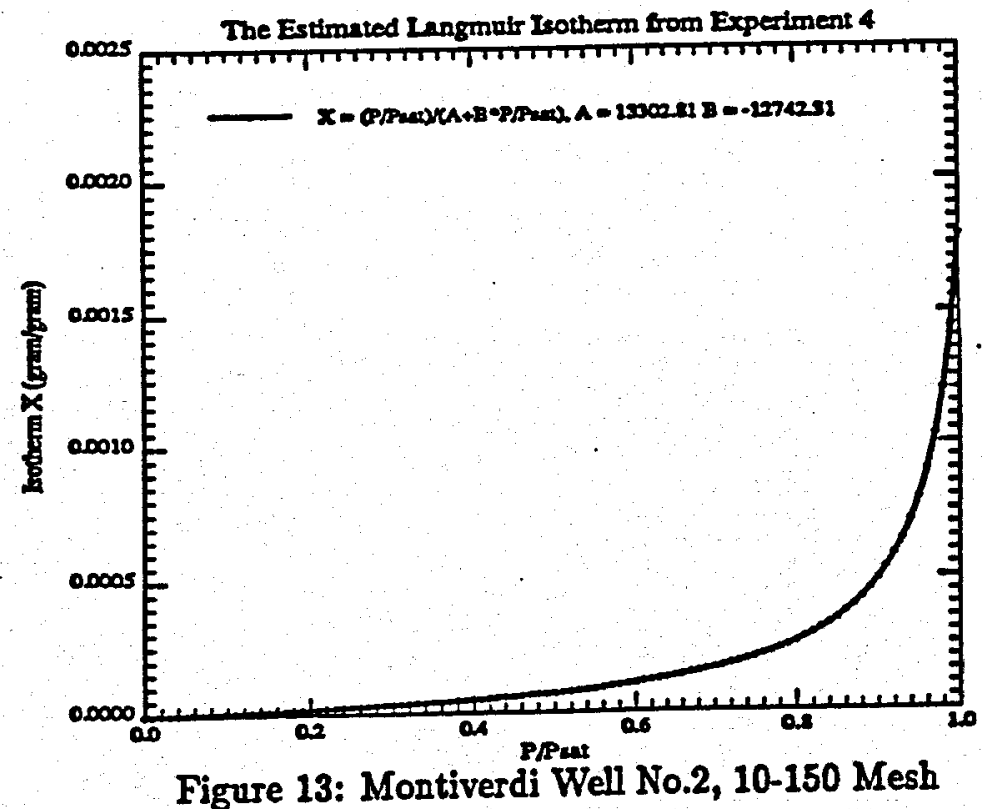



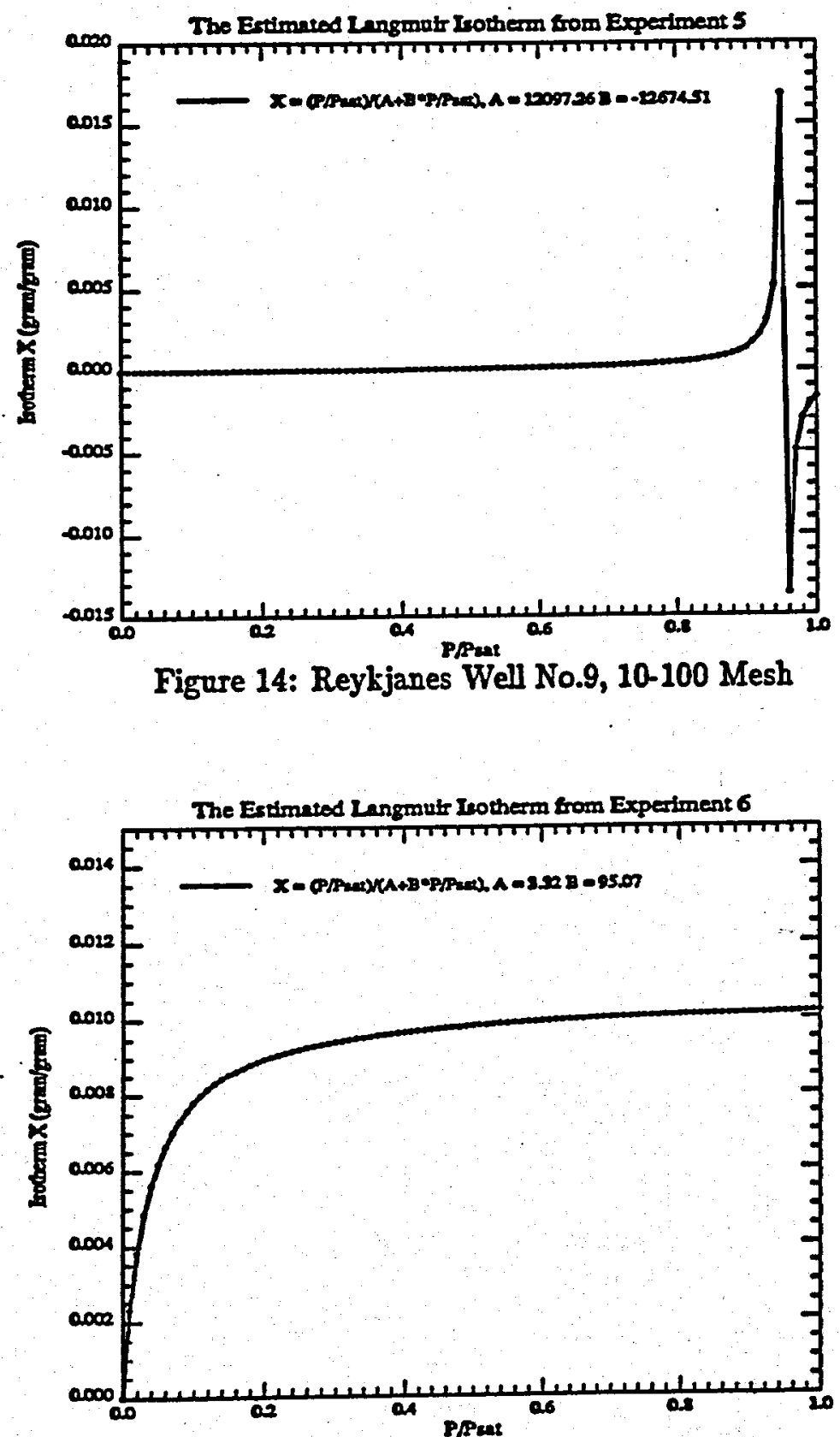

Figure 15: Geysers Well Megu-15 ST2, Depth 8600 - 8800 Feet, 20-150 Mesh. 


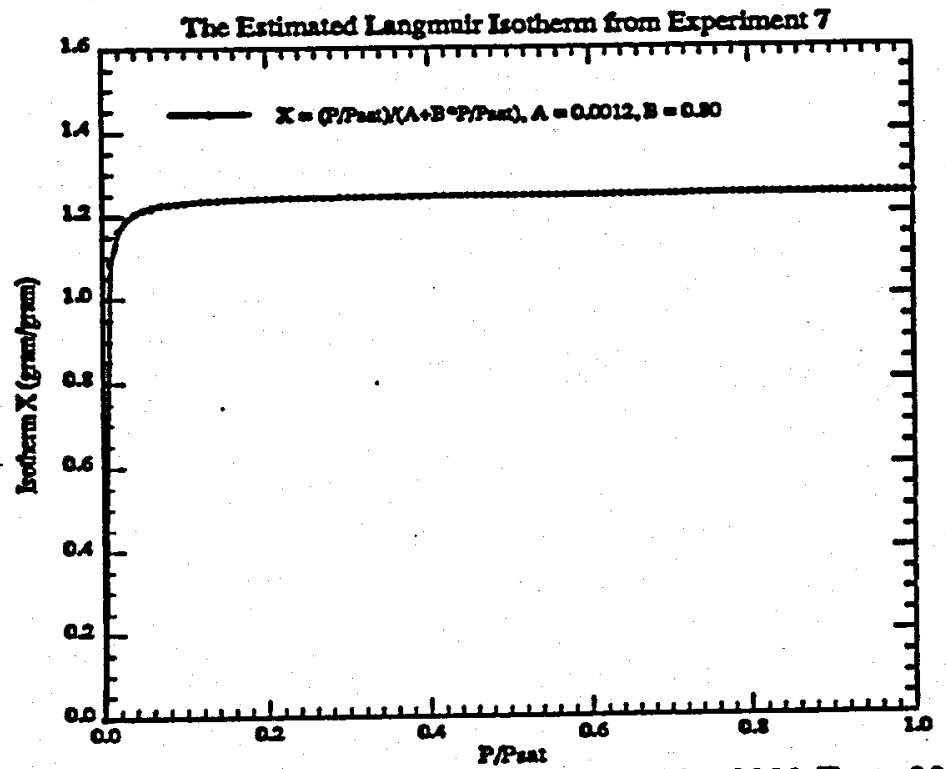

Figure 16: Geysers Well OF52-11, Depth 8000 - 8200 Feet, 30-80 Mesh

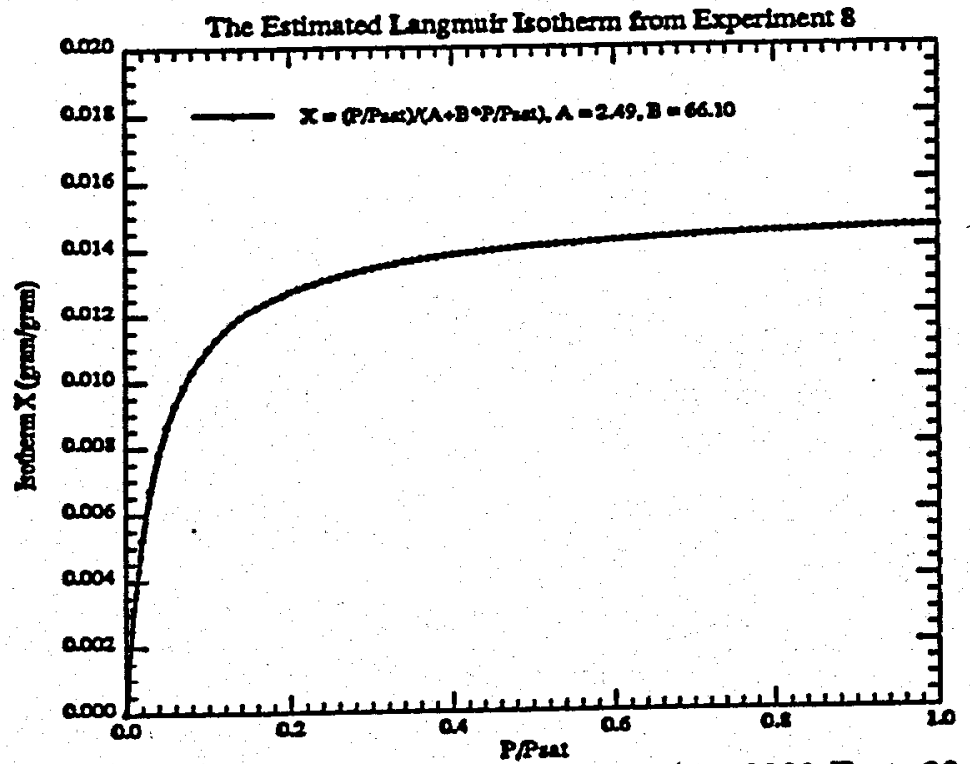

Figure 17: Geysers Well OF52-11, Depth 8000 - 8200 Feet, 30-150 Mesh 


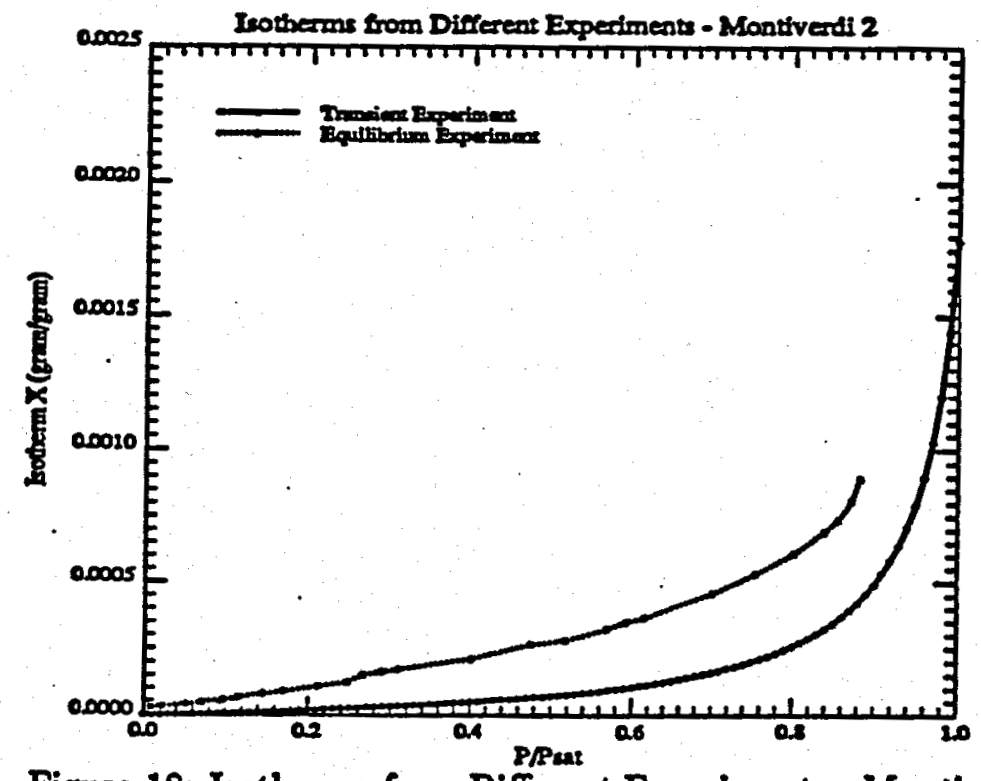

Figure 18: Isotherms from Different Experiments - Montiverdi 2

The same rock sample was used in both transient and equilibrinm experiments. The two results are plotted together in Figure 18. The curves have very similar shape and the data are reasonably close. This is an encouraging sign although no firm conclusion can be made based on this single plot. As additional measurements are made, further comparisons will be possible.

\subsection{Effect of Permeability}

The samples were prepa red by pouring the presieved sample into the core holder with the holder being tapped to consolidate the sample as much as possible to gain the largest weight. Permeability is measured after each transient run.

Three types of isotherm were observed as shown in Figures 10 through 17: convex to the pressure axis, concave to the pressure axis and straight line. To examine the effect of permeability on the shape of the isotherms, different permeabilities were used in the nonlinear regression model. The results are shown in Figures 19, 20 and 21. From these figures we can see that although permeability has an effect on the magnitude of the adsorption, the shape of the isotherm curve does not change. This means that even when 


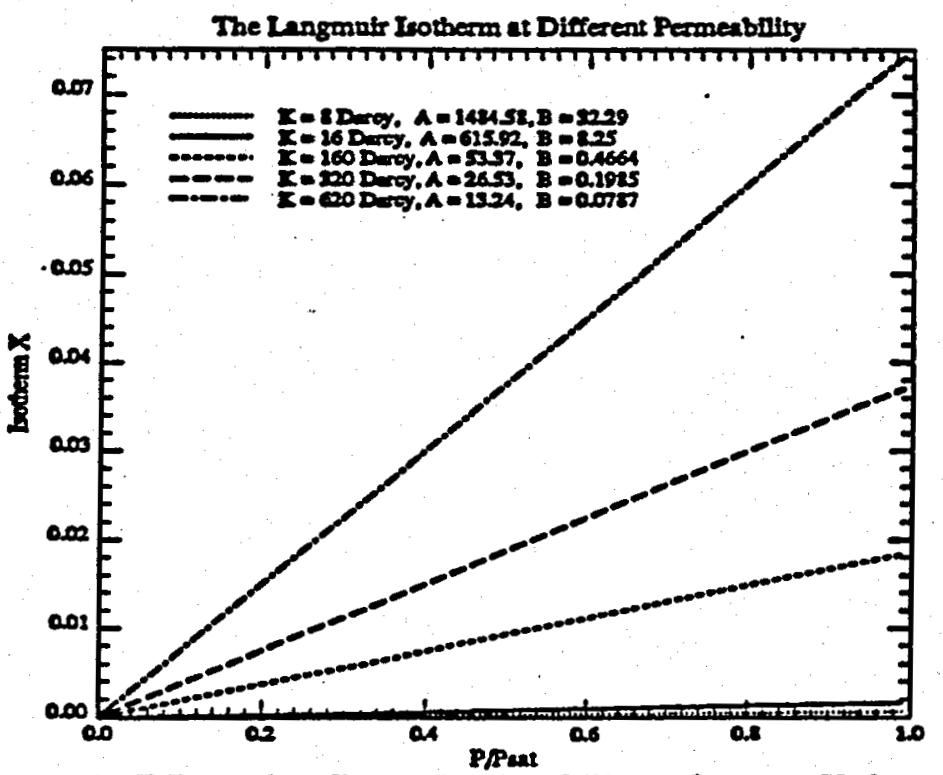

Figure 19: Effect of Different Permeability - Geysers Unknown Well

there is an error in permeability or when there is no accurate permeability data available, we can still use this method to estimate the correct shape of the isotherm curve.

\subsection{Effect of Porosity}

Porosities are calculated by knowing the volume of the sample holder and the weight of the samples. To check the effect of any measurement error, the program was run by using different porosity values. Again the results show that the porosity only affects the magnitude of the adsorption but has no effect on the shape of the isotherm curves. The results of the isotherm plot using different porosities are shown in Figures 22, 23 and 24.

\subsection{Conclusions}

- Using the one-dimensional steam flow simulator developed by Nghiem and Ramey (1991) combined with nonlinear regression, the Langmuir isotherm parameters can be estimated by matching the pressure transient experiment data. 


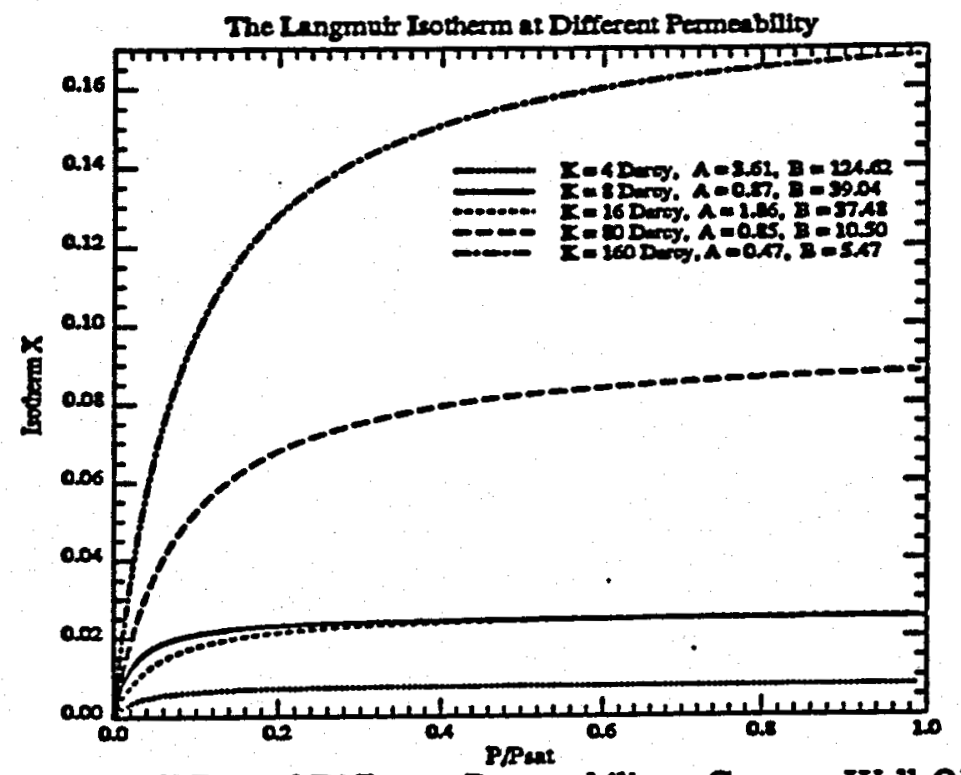

Figure 20: Effect of Different Permeability - Geysers Well OF52-11

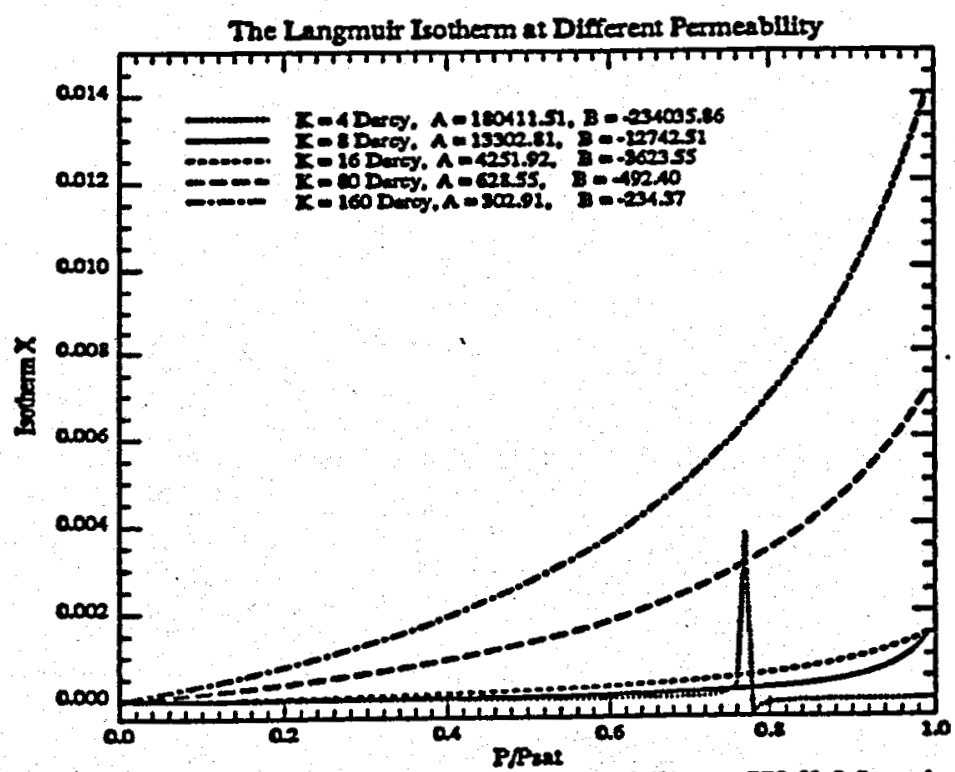

Figure 21: Effect of Different Permeability - Well Montiverdi 2 


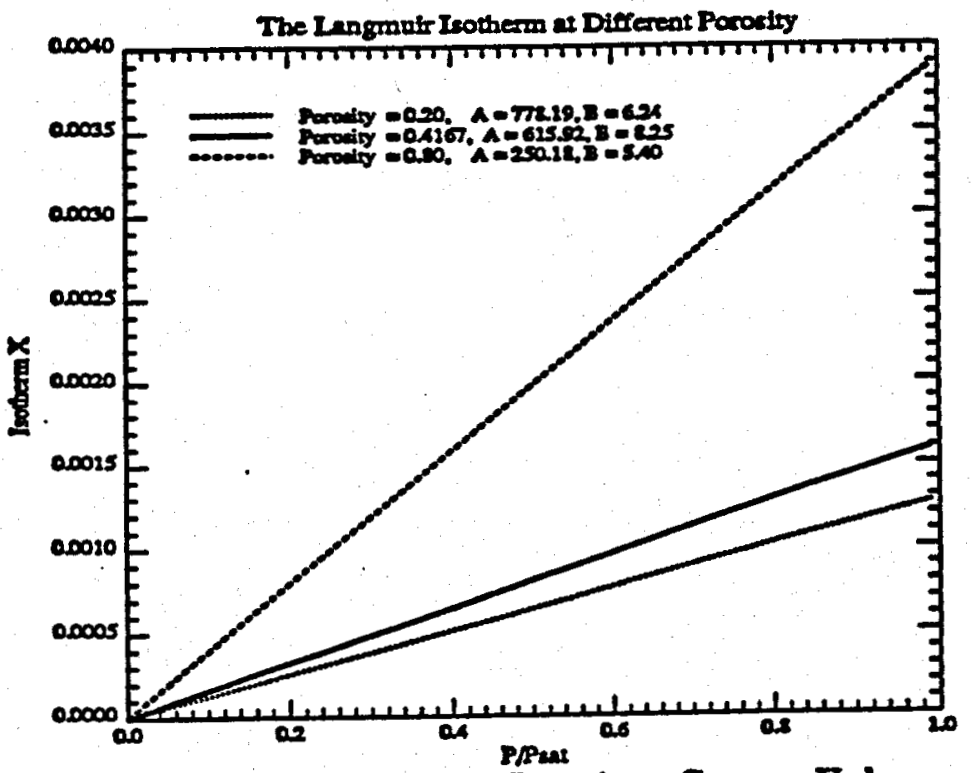

Figure 22: Effect of Different Porosity - Geysers Unknown Well

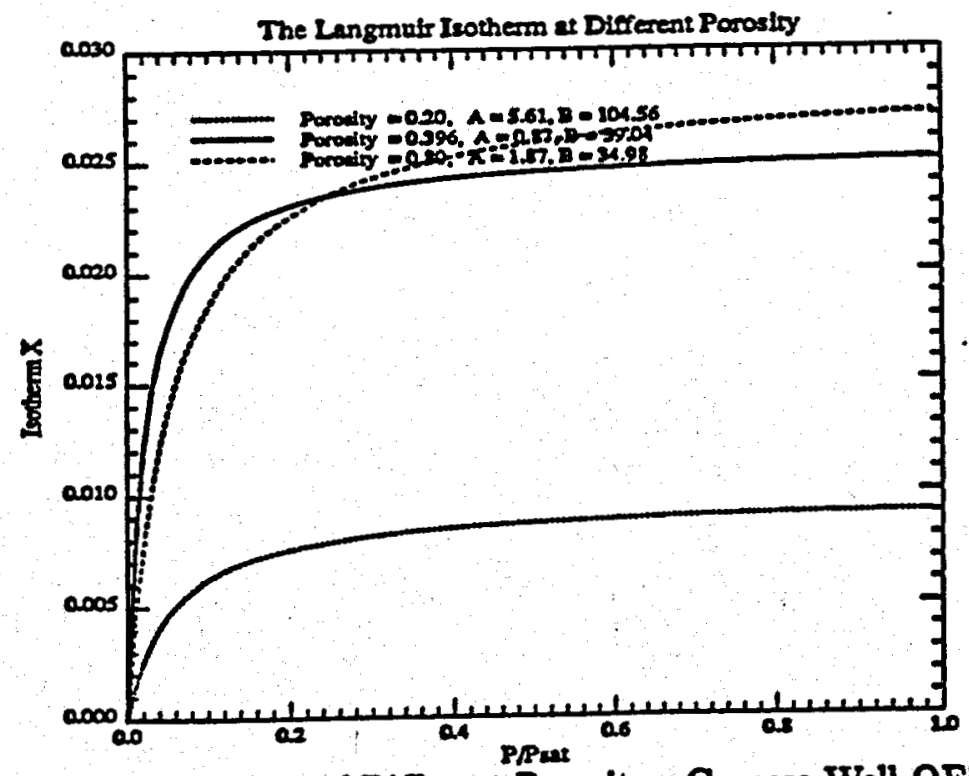

Figure 23: Effect of Different Porosity - Geysers Well OF52-11 


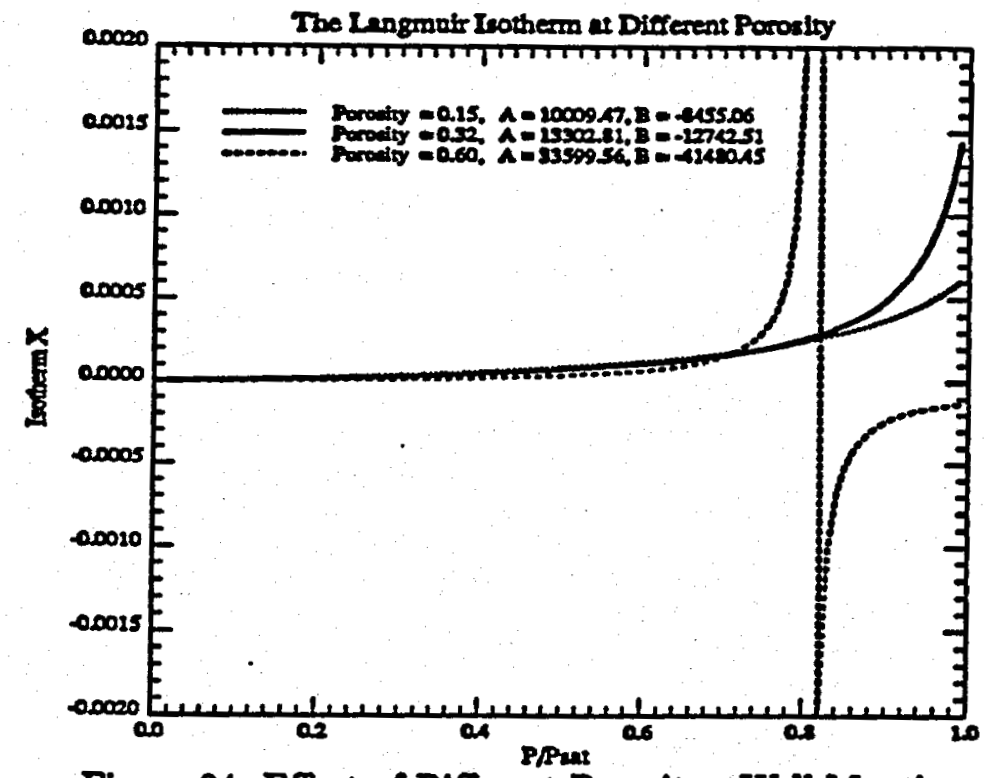

Figure 24: Effect of Different Porosity - Well Montiverdi 2

- The permeability does not affect the shape of the isotherm curve obtained from the nonlinear regression method.

- The porosity does not affect the shape of the isotherm curve obtained from the nonlinear regression method.

\subsection{Future Work}

- Whenever possible, larger samples should be used to decrease the effect of the open space between the ends of the sample holder and the pressure transducers.

- The experiment procedure used in the experiment did not taking account the effect of the extra space mentioned above thus the pressures measured were lower than the "real" pressures before the sample holder's valves were opened. This procedure needs to be modified to give more accurate pressure measurement results.

- The pressure transient experiments using noncondensable gas and salt deposited onto the internal surfaces of the rock samples will be carried 
out.

- The one-dimensional steam flow simulator considers only the material balance and not the energy balance. The energy balance needs to be added.

\section{References}

- Eiper, M.E.: "Computer Generation of Type Curves." MS report, Stanford U. Geothermal Program Report SGP-TR-86, Stanford, CA (1985)

- Harr, M. S.: "Laboratory Measurement of Sorption in Porons Media," MS report, Stanford U. Geothermal Program Report SGP-TR-138, Stanford, CA (1991)

- Leaver, J. D. Grader, A. and Ramey Jr., H. J.: "Multiple-Well Interference Testing in the Ohaaki Geothermal Field." SPE Formation Evaluation (June 1988) 429-437.

- Nghiem, C.P. and Ramey, H.J.Jr.: One-Dimensional Steam Flow in Porous Media, SGP No. TR-132, Stanford Geothermal Program, Stanford University, (1991).

- Vela, S.: "Effect of Linear Boundary on Interference and Prlse Tests -The Elliptical Inference Area." JPT (Aug. 1977) 947-950. 